\title{
Continuous Acetone-Butanol-Ethanol (ABE) Fermentation with in Situ Solvent Recovery by Silicalite-1 Filled PDMS/PAN Composite Membrane
}

\author{
Li, Jing; Chen, Xiangrong; Qi, Benkun; Luo, Jianquan; Zhuang, Xiaojie; Su, Yi; Wan, Yinhua
}

Published in:

The Open Fuels \& Energy Science Journal

Link to article, DOI:

10.1021/ef401706k

Publication date:

2014

Document Version

Publisher's PDF, also known as Version of record

Link back to DTU Orbit

Citation (APA):

Li, J., Chen, X., Qi, B., Luo, J., Zhuang, X., Su, Y., \& Wan, Y. (2014). Continuous Acetone-Butanol-Ethanol (ABE) Fermentation with in Situ Solvent Recovery by Silicalite-1 Filled PDMS/PAN Composite Membrane. The Open Fuels \& Energy Science Journal, 28(1), 555-562. https://doi.org/10.1021/ef401706k

\section{General rights}

Copyright and moral rights for the publications made accessible in the public portal are retained by the authors and/or other copyright owners and it is a condition of accessing publications that users recognise and abide by the legal requirements associated with these rights.

- Users may download and print one copy of any publication from the public portal for the purpose of private study or research.

- You may not further distribute the material or use it for any profit-making activity or commercial gain

- You may freely distribute the URL identifying the publication in the public portal 


\title{
Continuous Acetone-Butanol-Ethanol (ABE) Fermentation with in Situ Solvent Recovery by Silicalite-1 Filled PDMS/PAN Composite Membrane
}

\author{
Jing Li, ${ }^{\dagger, \dagger, \S}$ Xiangrong Chen, ${ }^{\dagger}$ Benkun Qi, ${ }^{\dagger}$ Jianquan Luo, ${ }^{\dagger}$ Xiaojie Zhuang, ${ }^{\dagger, \dagger}$ Yi Su, ${ }^{\dagger}$ and Yinhua Wan ${ }^{*}{ }^{\dagger}$ \\ ${ }^{\dagger}$ State Key Laboratory of Biochemical Engineering, Institute of Process Engineering, Chinese Academy of Sciences, Beijing 100190, \\ People's Republic of China \\ "University of Chinese Academy of Sciences, Beijing 10049, People's Republic of China \\ ${ }^{\S}$ College of Biology Science \& Engineering, Hebei University of Economics \& Business, Shijiazhuang 050061, People’s Republic of \\ China
}

\begin{abstract}
The pervaporation (PV) performance of a thin-film silicalite-1 filled PDMS/PAN composite membrane was investigated in the continuous acetone-butanol-ethanol (ABE) production by a fermentation-PV coupled process. Results showed that continuous removal of $\mathrm{ABE}$ from the broth at three different dilution rates greatly increased both the solvent productivity and the glucose utilization rate, in comparison to the control batch fermentation. The high solvent productivity reduced the acid accumulation in the broths because most acids were reassimilated by cells for ABE production. Therefore, a higher total solvent yield of $0.37 \mathrm{~g} / \mathrm{g}$ was obtained in the fermentation-PV coupled process, with a highly concentrated condensate containing 89.11-160.00 g/L ABE. During $268 \mathrm{~h}$ of the fermentation-PV coupled process, the PV membrane showed a high ABE separation factor of more than 30 and a total flux of $486-710 \mathrm{~g} / \mathrm{m}^{2} \mathrm{~h}$. Membrane fouling was negligible for the three different dilution rates. The solution-diffusion model, especially the mass transfer equation, was proved to be applicable to this coupled process.
\end{abstract}

\section{INTRODUCTION}

The depletion of petroleum fuel reserves and the serious environmental issues have triggered an increased attention in technologies that use renewable resources for liquid fuel production. ${ }^{1,2}$ Butanol has been regarded as one of the most promising biofuels, due to its characteristics of an alternative liquid fuel to meet the needs of sustainable and green energy systems. ${ }^{3,4}$ However, butanol is highly toxic to the fermenting microorganism, resulting in low product concentration in the fermentation broth. Therefore, the conventional butanol fermentation process suffers from low productivity and large energy consumption in the subsequent distillation operation. It was reported that, if the level of butanol concentration in the reactor could be increased from $1.2 \%$ to $2 \%(\mathrm{w} / \mathrm{v})$, the cost of distillation energy for solvent recovery would be reduced by half. $^{5}$ It is generally believed that integrating the fermentation with the product separation process by using a suitable in situ product recovery (ISPR) technique could overcome the shortage of low solvent $(\mathrm{ABE})$ resistance of these strains. To date, various techniques, such as gas-stripping, pervaporation (PV), liquid-liquid extraction, and adsorption, ${ }^{6}$ have been investigated to reduce the effect of butanol inhibition, and enhance solvent productivity and sugar utilization. Among those techniques, PV is considered to be the most promising technique because of its energy efficiency, cost effectiveness, as well as no harmful effects on the microorganisms. ${ }^{7}$

Among various PV membranes, poly(dimethylsiloxane) (PDMS) membranes have shown good comprehensive performance, including good thermal, chemical, and mechanical stability, moderate selectivity and flux, as well as ease of manufacture and cost effectiveness. The feasibility of PDMS membranes in continuous removal of butanol from the $\mathrm{ABE}$ fermentation broth was examined in previous studies. ${ }^{8-10}$ Hecke et al. reported continuous two-stage ABE fermentation coupled to the PV process using a PDMS composite membrane. The coupled process lasted $475 \mathrm{~h}$ with an average flux of $367 \mathrm{~g} / \mathrm{m}^{2} \mathrm{~h}^{8}$. Chen et al. investigated ABE fermentation by combining a PDMS membrane fermentor in a closedcirculating fermentation system. ${ }^{9}$ The low flux and/or low separation factor of the PV membrane used in the above reports require a larger membrane area or a higher operation temperature, or obtaining a low total butanol concentration in the permeate solution from the pervaporation unit and require more energy per weight unit of butanol in the subsequent distillation procedure, thus increasing the cost of the PV process and reducing its viability in industrial applications.

Recently, a thin-film composite membrane with the incorporation of silicalite-1 was developed for separating butanol from a model solution. ${ }^{11,12}$ The relatively higher flux and higher separation factor of this composite membrane compared to those of the pure PDMS membrane shows its great promise in commercial application in in situ $\mathrm{ABE}$ recovery from broth.

In this work, high-performance ultra-thin-film silicaliet-1 filled PDMS composite membrane was prepared by curing a prepolymer on a porous PAN substrate. The behaviors of

Received: August 26, 2013

Revised: December 6, 2013

Published: December 6, 2013 


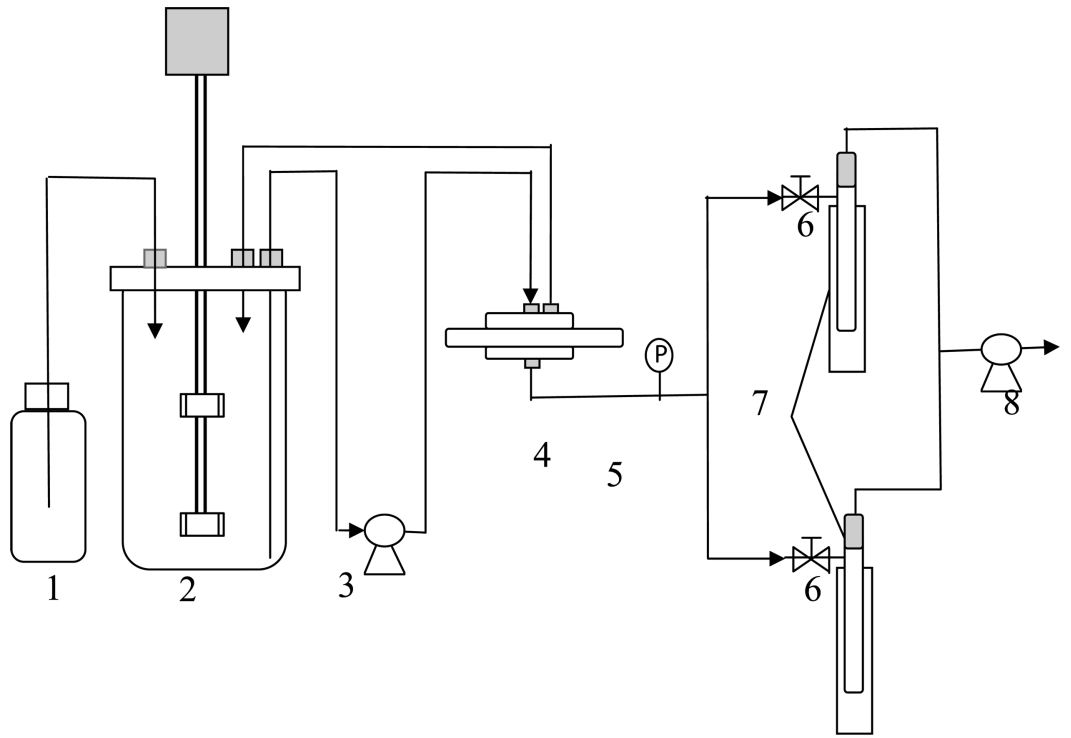

Figure 1. Schematic diagram of the apparatus for pervaporation experiment: (1) concentrate glucose feed tank, (2) fermentator, (3) peristaltic pump, (4) pervaporation unit, (5) pressure gauge, (6) triple valve, (7) cold trap, (8) vacuum pump.

continuous $\mathrm{ABE}$ fermentation with in situ solvent recovery by $\mathrm{PV}$ with the composite membrane were investigated. The performances of the silicalite-1 filled PDMS/PAN membrane were also studied in continuous the $\mathrm{ABE}$ fermentation-PV coupled process.

\section{EXPERIMENTAL SECTION}

2.1. Materials. PDMS was purchased from GE Toshiba Silicones Co., Ltd., Japan. Silicalite-1 was prepared in our laboratory according to the method reported by Zhou et al. ${ }^{11}$ The size of silicalite-1 particles was about $1 \mu \mathrm{m}$. An asymmetric microporous poly(acrylonitrile) (PAN) membrane (20 kDa, Shanghai Jitian Co. Ltd., China) was employed as the support substrate. Acetone, butanol, ethanol, and nheptane were of analytical reagent grade and purchased from Beijing Chemical Plant, Beijing, China. Deionized water was used in all experiments.

2.2. Preparation of Thin-Film Silicalite-1 Filled PDMS/PAN Composite Membrane. A silicalite-1 filled PDMS/PAN composite membrane was prepared by first mixing $1.8 \mathrm{~g}$ of PDMS, $36 \mathrm{~g}$ of $n$ heptane, and $2.25 \mathrm{~g}$ of silicalite- 1 in a three-neck round-bottom flask, and then the resulting solution was stirred at $70{ }^{\circ} \mathrm{C}$ for about $2 \mathrm{~h}$. After degassing under vacuum, the mixing solution was coated as thin layers on the top of a PAN support membrane, using an automatic film applicator (K303 Multi Coater, RK Print Coat Instruments Ltd., UK), with a coating gear of 10 . Subsequently, the composite membrane was dried overnight at room temperature, and then cured at $80{ }^{\circ} \mathrm{C}$ in a vacuum oven for more than $8 \mathrm{~h}$ to ensure complete curing. The finished membrane was cut into round discs with diameters of 48 or 88 $\mathrm{mm}$ for PV tests, respectively.

2.3. PV Experiments. The membrane module with an effective membrane area of 0.0072 and $0.0243 \mathrm{~m}^{2}$ was used, respectively. Details of the membrane module have been given previously. ${ }^{13}$ When coupled with fermentation, as reported by $\mathrm{Li}$ et al., ${ }^{14} 30 \%$ ethanol solution was used to sterilize the PV membrane by circulating the ethanol solution through the system for $12 \mathrm{~h}$, followed by washing with $500 \mathrm{~mL}$ of sterilized deionized water. The feed tank with butanol/ water solution or $\mathrm{ABE}$ model solution was maintained at $37^{\circ} \mathrm{C}$ by the heater band, and a peristaltic pump was used for recirculation of the liquid mixture. The pressure at the permeate side was maintained at less than $280 \mathrm{~Pa}$ all the time. Samples were collected by two parallel cold traps in a liquid nitrogen bath and analyzed during the PV experiment. Flux $(J)$ and selectivity $(\alpha)$ were calculated as follows

$$
J=w / A t
$$

$$
\alpha=[y /(1-y)] /[x /(1-x)]
$$

where $W$ is the weight of the condensate $(\mathrm{g}), A$ is the membrane area $\left(\mathrm{m}^{2}\right), t$ is the time (h) for the sample collection, and $x$ and $y$ are weight fractions of components in retentate and permeate samples, respectively.

The solution-diffusion model has been adopted in many studies to simulate the butanol separation from the butanol/water solution, ${ }^{14,15}$ the transport behavior of permeates across the PV membrane can be expressed as

$$
J_{\mathrm{i}}=K_{\mathrm{i}, \mathrm{ov}} C_{\mathrm{i}}
$$

where $J_{\mathrm{i}}$ is the flux of permeate $\mathrm{i}$ with the units of $\mathrm{g} / \mathrm{m}^{2} \mathrm{~h}, K_{\mathrm{i}, \text { ov }}$ is the overall mass transfer coefficient of permeate $i$ with the units of $\mathrm{mm} / \mathrm{h}$, and $C_{i}$ is the concentration of permeate $i$ in the reactor-side solution with the units of $\mathrm{g} / \mathrm{L}$.

2.4. Culture and Inoculum Preparation. Inoculum was prepared from a spore suspension of a hyper-butanolagenic mutant $C$. acetobutylicum DP 217. Spores were suspended in $70 \mathrm{~g} / \mathrm{L}$ corn mash medium at $4{ }^{\circ} \mathrm{C}$. Spores $(10 \mathrm{~mL})$ were heat-shocked for $90 \mathrm{~s}$ at 100 ${ }^{\circ} \mathrm{C}$, followed by cooling in ice-water for $60 \mathrm{~s}$. The culture was inoculated into $100 \mathrm{~mL}$ of cooked $70 \mathrm{~g} / \mathrm{L}$ corn mash medium in a 150 $\mathrm{mL}$ screw capped Pyrex bottle, and then incubated anaerobically for $20-24 \mathrm{~h}$ at $37^{\circ} \mathrm{C}$ as the primary seed culture. A $20 \mathrm{~mL}$ portion of the primary seed culture was transferred into $250 \mathrm{~mL}$ sealed anaerobic bottles containing $200 \mathrm{~mL}$ of $70 \mathrm{~g} / \mathrm{L}$ corn mash medium and incubated at $37^{\circ} \mathrm{C}$ for $20-24 \mathrm{~h}$ as the secondary seed culture. When the suspension appeared, the secondary seed culture was inoculated into the $\mathrm{ABE}$ production medium.

2.5. Fermentation-PV Coupled Processes. A schematic diagram of the fermentation-PV coupling apparatus is presented in Figure 1. Control batch fermentations were conducted in a $2 \mathrm{~L}$ fermentor (New Brunswick Scientific, Edison, NJ). The fermentation medium contained the following: glucose $60 \mathrm{~g} / \mathrm{L}$, yeast extract $3 \mathrm{~g} / \mathrm{L}$, $\mathrm{CH}_{3} \mathrm{COONa} 1.1 \mathrm{~g} / \mathrm{L}, \mathrm{NaCl} 0.05 \mathrm{~g} / \mathrm{L}, \mathrm{KH}_{2} \mathrm{PO}_{4} 0.25 \mathrm{~g} / \mathrm{L}, \mathrm{K}_{2} \mathrm{HPO}_{4}$ $0.25 \mathrm{~g} / \mathrm{L}, \mathrm{MgSO}_{4} 0.05 \mathrm{~g} / \mathrm{L}, \mathrm{FeSO}_{4} \cdot 7 \mathrm{H}_{2} \mathrm{O} 0.05 \mathrm{~g} / \mathrm{L}$, and $\mathrm{MnSO}_{4} \cdot \mathrm{H}_{2} \mathrm{O}$ $0.05 \mathrm{~g} / \mathrm{L}$. The reaction volume and the membrane areas varied with different dilution rates, and all parameters are listed in Table 1. The fermentation medium was autoclaved at $121^{\circ} \mathrm{C}$ for $20 \mathrm{~min}$, followed by cooling to $37{ }^{\circ} \mathrm{C}$ under an $\mathrm{O}_{2}$-free $\mathrm{N}_{2}$ atmosphere. The fermentor was inoculated with $10 \%(\mathrm{v} / \mathrm{v})$ of the secondary seed culture.

The fermentation experiment was allowed to run for $20 \mathrm{~h}$ to reach the initiation of the solventogenesis phase of $\mathrm{ABE}$ fermentation, and then the sterile membrane unit coupled to the fermentor was put into operation and in situ ABE removal by PV started. Fermentation broth 
Table 1. Parameters Used in Continuous ABE Production by Fermentation-PV Coupled Process

\begin{tabular}{llll} 
& test I & test II & test III \\
fermentation volume $(\mathrm{L})$ & 1 & 1.5 & 1 \\
membrane area $\left(\mathrm{m}^{2}\right)$ & 0.0072 & 0.024 & 0.024 \\
dilution rate $\left(\mathrm{h}^{-1}\right)$ & 0.0038 & 0.0081 & 0.0117 \\
\hline
\end{tabular}

was circulated in the fermentor through the membrane module using a peristaltic pump at $2 \mathrm{~L} / \mathrm{min}$. Glucose and the organism cells were retained in the fermentor by the PV membrane. The volatile compounds, mainly acetone, butanol, and ethanol, were permeated through the PV membrane, and then cooled in the cooling traps, and no glucose was detected in the permeate solution. Highly concentrated fresh feed solution was added into the fermentor continuously at the same flow rate of in situ removal of solvent to maintain the constant broth volume and the sugar content in the fermentation broth. Continuous experiments with three different dilution rates were conducted, respectively, when the steady condition was maintained. The performance of the thin-film composite membrane during the continuous coupled experiments was investigated.

2.6. Analysis. Acetone, butanol, and ethanol concentrations were determined using a gas chromatograph equipped with a flame ionization detector (FID) and a $20 \mathrm{ft}$ stainless steel packed column (7890A, Agilent Technologies, USA). The oven temperature was programmed from 100 to $250{ }^{\circ} \mathrm{C}$ at a rate of $16^{\circ} \mathrm{C} / \mathrm{min}$. Both injector and detector temperatures were set at $250{ }^{\circ} \mathrm{C}$. Organic acids in the fermentation culture solutions were analyzed by high-performance liquid chromatography (LC-20A, Shimadazu Corp., Japan). The ultraviolet detector was used to detect acetic acid and butyric acid (SPD-20A, Shimadazu Corp., Japan). Perchloric acid solution (5 mM) was used as the mobile phase at $0.6 \mathrm{~mL} / \mathrm{min}$. Cell density was measured at $620 \mathrm{~nm}$ using an ultraviolet spectrophotometer (UV757 CRT, Shanghai Precision \& Scientific Instrument Co., Ltd., China). Glucose concentration was measured using a biosensor with glucose oxide electrodes (SBC-40C, Institute of Biology, Shandong Academy of Science, China).

\section{RESULTS AND DISCUSSION}

3.1. Characterization and Evaluation of Thin-Film Silicalite-1 PDMS/PAN Composite Membrane. In this work, membranes have been prepared by using PAN as the support substrate and silicalite- 1 as filler. The surface and the cross-sectional morphology of the composite membranes was characterized by SEM. Figure 2a is an SEM surface image of the membrane. There was a dense membrane structure free of pores and cracks, and silicalite-1 particles were evenly dispersed in the PDMS polymer. Figure $2 \mathrm{~b}$ represents the cross-section image of the composite membrane. In this micrograph, the composite membrane showed two obvious layers from top to bottom: silicalite-1 filled polymer layer and substrate layer. The thickness of the active layer was about $7 \mu \mathrm{m}$, which guaranteed the high flux of the membrane.

To evaluate the PV performance of the silicalite-1 PDMS/ PAN composite membrane, the butanol/water binary solutions were first tested in the experimental system. PV experiments were conducted with varied butanol concentrations ranging from 2.3 to $10.4 \mathrm{~g} / \mathrm{L}$, which are relevant to that in the control ABE fermentation. Membrane performance for the model solution is shown in Figure 3.

As can be seen from Figure 3a, the butanol separation factor of the thin-film membrane decreased slightly from 33 to 30 with increasing feed concentration. In the condensate, $244 \mathrm{~g} / \mathrm{L}$ of butanol concentration was obtained. Vane et al. evaluated the economics of pervaporation, and claimed that the PV system could be sufficiently energy efficient when the separation
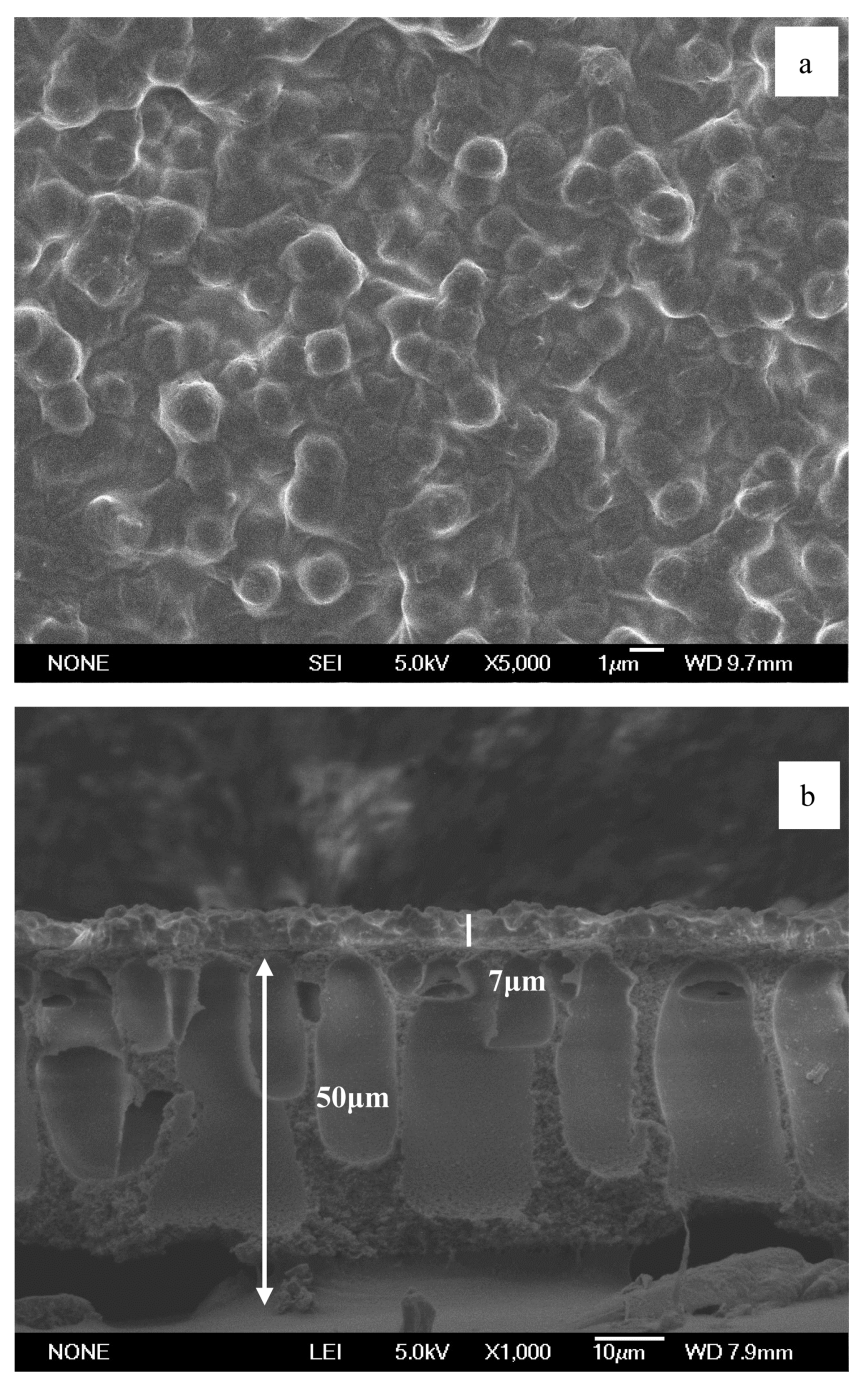

Figure 2. SEM images of the silicalite-1 filled PDMS/PAN membrane: (a) top view, (b) cross section.

factors of membranes were higher than $30 .{ }^{16}$ It seemed that the silicalite-1 filled PDMS/PAN composite membrane could meet this requirement. As shown in Figure $3 b$, under the experimental conditions examined, the total flux and the butanol flux increased from 550 to $708 \mathrm{~g} / \mathrm{m}^{2} \mathrm{~h}$ and from 40 to $173 \mathrm{~g} / \mathrm{m}^{2} \mathrm{~h}$, respectively, while the water flux was more or less constant. According to the solution-diffusion mechanism, the increase of butanol flux is almost linear with butanol concentration. The transport behavior can be mathematically described by eq 3 , and the overall mass transfer coefficient of butanol was $16.84 \mathrm{~mm} / \mathrm{h}$. These phenomena were in agreement with the previous observations of the pervaporative separation of butanol-water solution. ${ }^{14}$ The total fluxes of the membrane were much higher than those of the reported membranes under the same conditions ${ }^{12,17}$ due to its very thin active separating layer (about $7 \mu \mathrm{m}$ ), which could meet the flux requirement of the fermentation-PV coupled processes. The results indicated that the thin-film silicalite-1 filled PDMS/PAN membrane possessed very good PV performance. Its applicability in the long term fermentation-PV coupled process was further investigated in the following experiments.

3.2. Continuous $A B E$ Fermentation by the Coupled Process. The $\mathrm{ABE}$ fermentation was first run as a controlled experiment without coupling with PV. Figure 4a shows the 

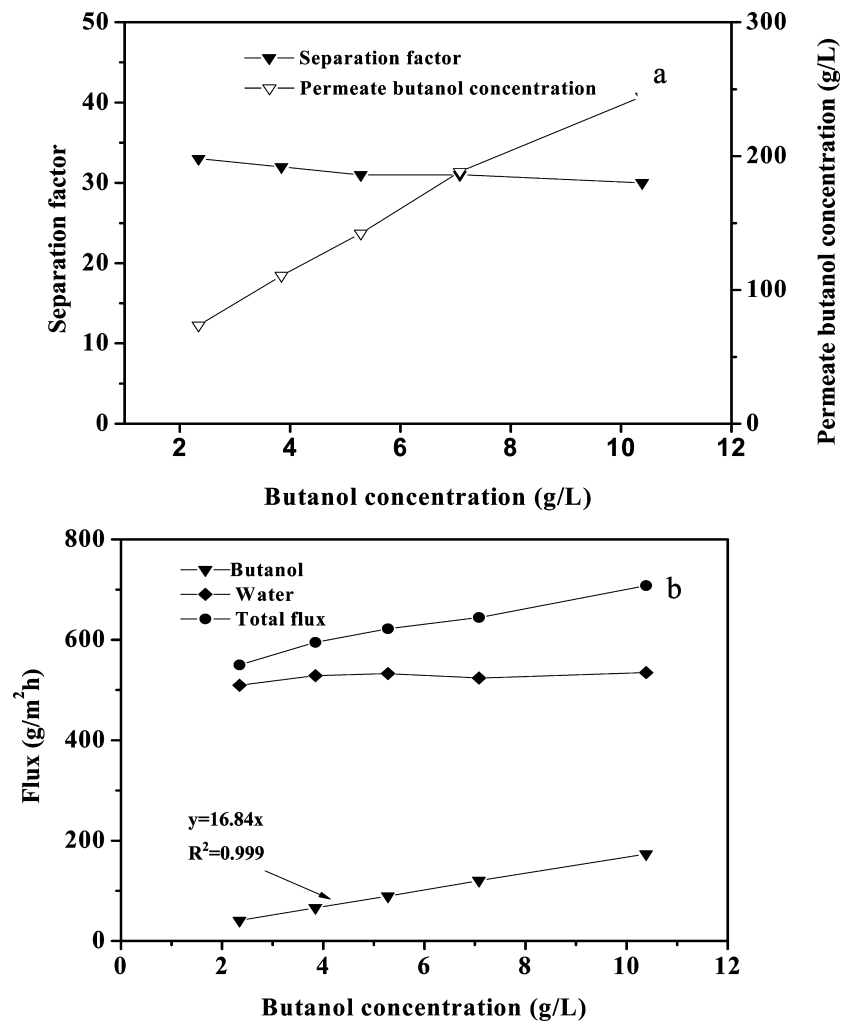

Figure 3. Pervaporation performance of the silicalite-1 filled PDMS/ PAN membrane with butanol/water model solutions at $37^{\circ} \mathrm{C}$. (a) Separation factor and permeate butanol concentration, and (b) flux.

growth of C. acetobutylicum DP 217 and the consumption of glucose. Maximum cell growth rate was obtained during the first $12 \mathrm{~h}$, followed by a stationary phase for $4 \mathrm{~h}$, then declined drastically at a fermentation time of $20 \mathrm{~h}$ because of the butanol inhibition on the microorganism. Simultaneously, the glucose utilization rate was high during the first $16 \mathrm{~h}$, and then slowed down after $20 \mathrm{~h}$ of inoculum. The average volumetric glucose consumption rate was $1.00 \mathrm{~g} / \mathrm{Lh}$ during the whole fermentation process. $\mathrm{ABE}$ and acid production profiles are shown in Figure $4 \mathrm{~b}, \mathrm{c}$. The culture produced $19.49 \mathrm{~g} / \mathrm{L}$ total solvent from $60 \mathrm{~g} / \mathrm{L}$ glucose, with a productivity of $0.32 \mathrm{~g} / \mathrm{Lh}$ and a yield of $0.32 \mathrm{~g} /$ g, respectively. Acid concentration increased greatly at the initial $12 \mathrm{~h}$ of fermentation, and maintained at a higher level of more than $1 \mathrm{~g} / \mathrm{L}$ between 12 and $36 \mathrm{~h}$, and then decreased slightly due to the assimilation by the organism (Figure 4c).

To evaluate the performance of simultaneous butanol fermentation and solvent recovery by $\mathrm{PV}$, continuous $\mathrm{ABE}$ production by the fermentation-PV coupled process was carried out. Fermentation was first started with batch mode and operated at $37^{\circ} \mathrm{C}$ in a $2 \mathrm{~L}$ fermentor with a working volume of $1 \mathrm{~L}$. When the fermentation progressed to $20 \mathrm{~h}$, the butanol concentration reached $4.41 \mathrm{~g} / \mathrm{L}$, and microorganism was in a physically active form and it was transformed from acidogenesis to solventogenesis, the fermentation-PV coupled process was started with a membrane having an area of $0.024 \mathrm{~m}^{2}$. Simultaneously, the broth volume in the fermentor was maintained constant by continuously introducing fresh feed at the same flow rate of in situ removal of solvent.

Continuous $\mathrm{ABE}$ fermentation by the coupled process was normally performed for at least $268 \mathrm{~h}$, and the data during 288 $\mathrm{h}$ of fermentation ( $20 \mathrm{~h}$ initial batch fermentation plus $268 \mathrm{~h}$ continuous fermentation) are presented in the present work. As
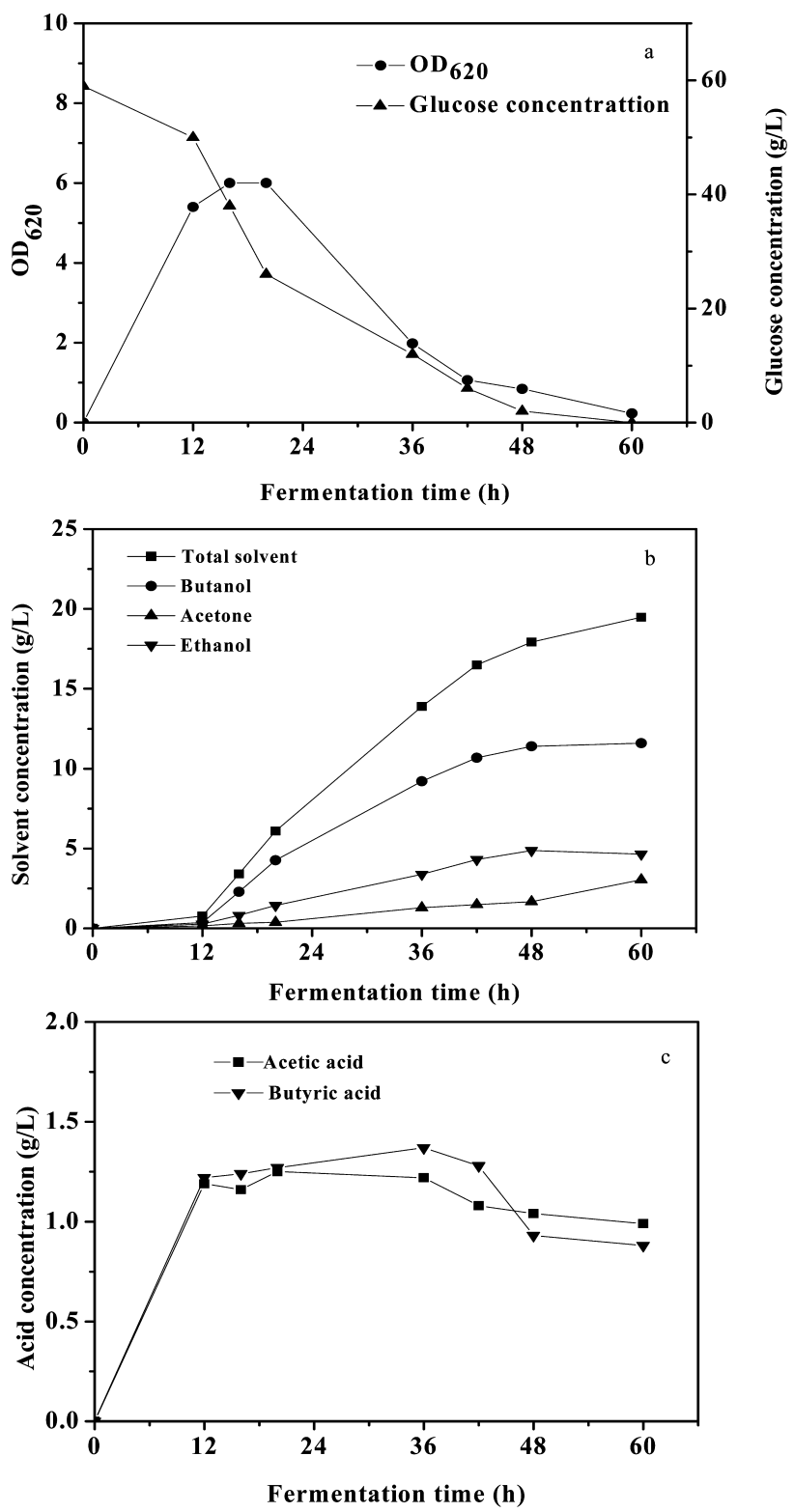

Figure 4. Production of $A B E$ in control batch fermentation: (a) $\mathrm{OD}_{620}$ and glucose concentrations, (b) solvent concentrations, (c) acid concentrations.

can be seen from Figure 5a, when PV was turned on, the cell density increased continuously with the operation time. This phenomenon could be explained by the constant removal of solvent from the fermentor by the PV process, avoiding butanol accumulation in the fermentor to inhibit the growth of bacteria cells. Moreover, in a preliminary study, it was found that the severe fluctuation of glucose concentration would result in the decline of activity of the organism and then a drastic variation of solvent production. This phenomenon was also found by Tashiro et al. and Hecke et al. ${ }^{18,19}$ Therefore, in the experiments, the precise regulation of glucose concentration at $26.56 \mathrm{~g} / \mathrm{L}$ was performed when feeding concentrated fresh medium of $200 \mathrm{~g} / \mathrm{L}$ glucose, which could support the rapid growth of cells. Furthermore, the cells were retained and accumulated in the fermentor due to retention of the PV membrane. Consequently, the maximum $\mathrm{OD}_{620}$ reached 14.3 , much higher than that in control batch fermentation without PV (1.98). The effect of PV on the fermentation was also 

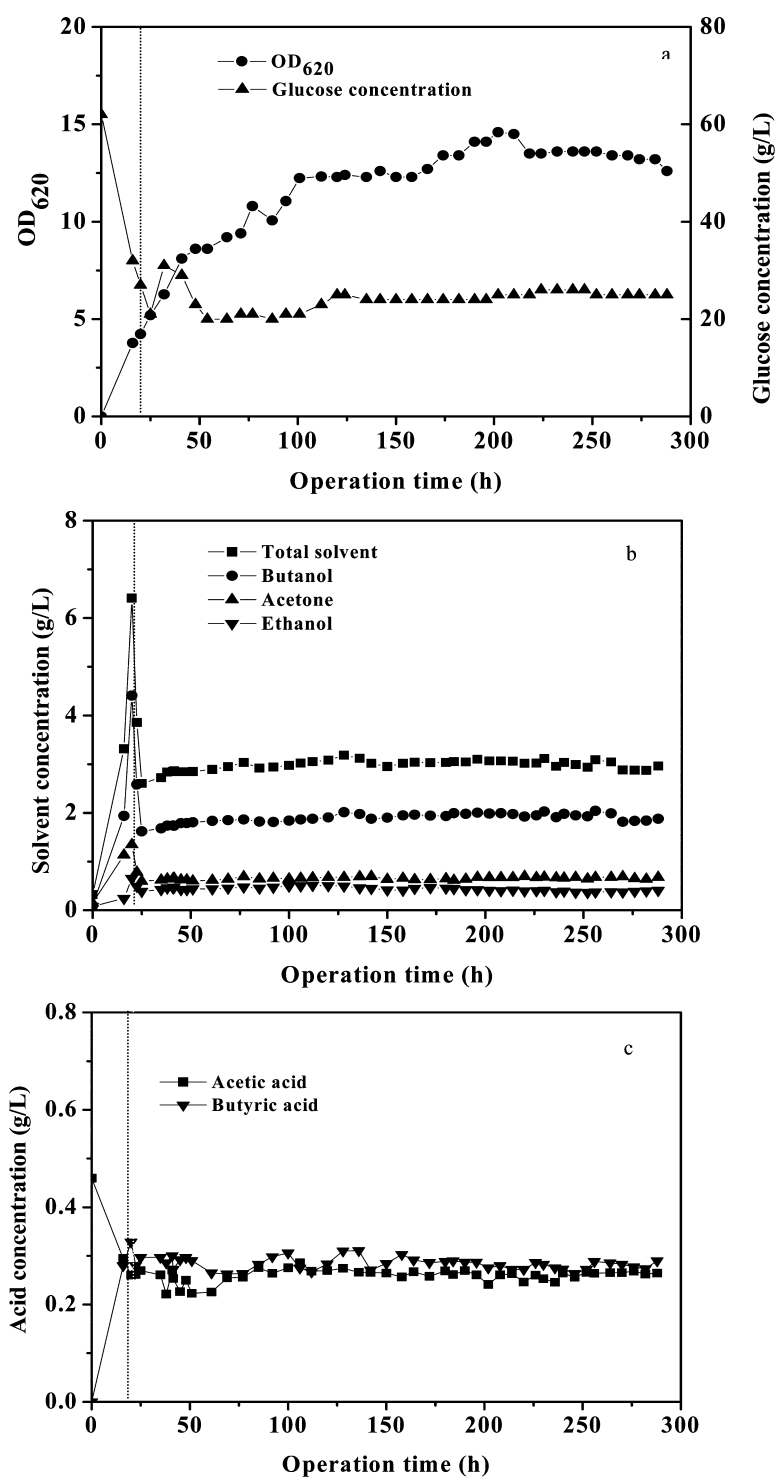

Figure 5. $\mathrm{ABE}$ fermentation profiles in continuous $\mathrm{ABE}$ fermentation-PV coupled process; $D=0.0117 \mathrm{~h}^{-1}$. The vertical line at $20 \mathrm{~h}$ represents the start line of pervaporation. (a) $\mathrm{OD}_{620}$ and glucose concentrations, (b) solvent concentrations, (c) acid concentrations.

examined in terms of volumetric glucose consumption rate, where the average volumetric glucose consumption rate was $2.55 \mathrm{~g} / \mathrm{Lh}$, which was $155 \%$ higher than that in the control batch process without PV. The increased glucose utilization rate could be due to the fact that, on account of the reduction of butanol inhibition, the cell population was much higher than that in the control batch fermentation without PV; thus, a higher cell population resulted in an increased glucose consumption rate. The average sugar conversion was $96.34 \%$.

The variation of solvent concentration observed during the long-term operation is illustrated in Figure $5 \mathrm{~b}$. The solvent concentration in the fermentor increased during the first $20 \mathrm{~h}$, reaching $6.41 \mathrm{~g} / \mathrm{L}$, and then decreased drastically due to its removal from the fermentation broth by the pervaporation process. Finally, the solvent concentration in the fermentation broth maintained at a stable level thanks to the regulation of the PV process. As can be seen from Figure 3, the flux of the membrane was related to the butanol concentration in the feeding solution. This implies that the solvent removal rate was related to the solvent concentration in the fermentor. As the solvent concentration in the fermentor increased, the solvent removal rate would also increase, which, in turn, resulted in the reduction of the solvent concentration in the fermentor, and vice versa. During this experiment, average acetone, ethanol, butanol, and total solvent concentrations in the fermentor were $0.67,0.43,1.96$, and $3.06 \mathrm{~g} / \mathrm{L}$, respectively, below the threshold of toxicity. This demonstrated that the thin-film silicalite- 1 filled PDMS/PAN composite membrane was highly effective for removing butanol from the fermentation broth.

With regard to acid production, the average concentrations of acetic acid and butyric acid were 0.26 and $0.28 \mathrm{~g} / \mathrm{L}$, respectively, in the fermentation broth at steady state (Figure 5c). These values were lower than those in the control batch fermentation. This phenomenon could be explained by the fact that the higher butanol productivity obtained resulted in an increasing reassimilation rate of acids in the fermentor when coupled to PV. Furthermore, a small amount of acetic acid was detected in the permeate solution $(0.20-0.71 \mathrm{~g} / \mathrm{L})$, indicating continuous removal of acetic acid from the fermentor through PV, which also led to a lower concentration of acids in the fermentation broth. However, there was no butyric acid detected in the permeate solution. Similarly, Querish et al. ${ }^{20}$ reported that acids concentrations were very low, almost not detected at the end of most of the operation of fed-batch fermentation with PV. Gapes et al. also reported ${ }^{21}$ that the butyric acid concentration remained very low after the startup of continuous online PV.

Figure 6 shows the variation of solvent concentration in the permeate solution. The solvent concentration in the permeate

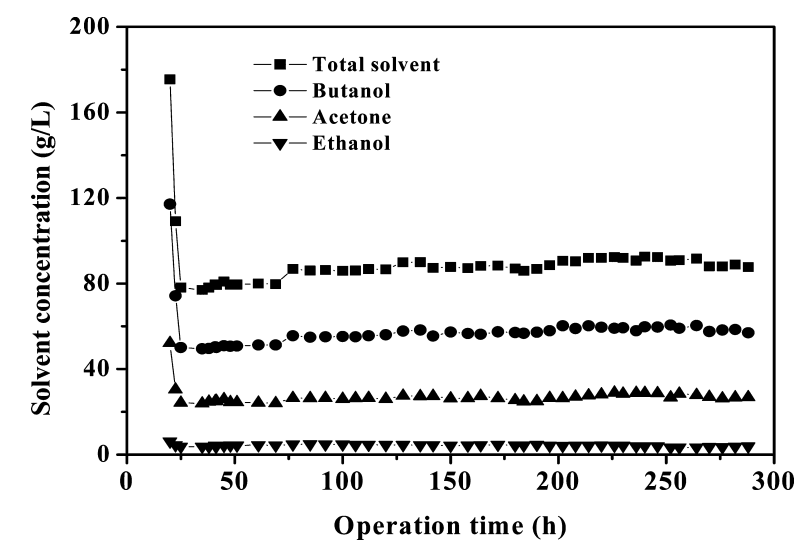

Figure 6. Permeate profiles in continuous ABE fermentation-PV coupled process; $D=0.0117 \mathrm{~h}^{-1}$.

solution decreased drastically from 175 to $78 \mathrm{~g} / \mathrm{L}$ within $15 \mathrm{~h}$ after the PV process started, and, eventually, maintained at a constant level. It was clearly observed that the change of butanol concentration in the permeate solution was closely related to its concentration in the fermentation broth. Average acetone, ethanol, butanol, and total solvent concentrations in the condensate solution (permeate solution) were 27.10, 4.24, 57.77 , and $89.11 \mathrm{~g} / \mathrm{L}$, respectively. The total solvent concentration obtained in the permeate solution was much higher than the maximum solvent concentration of $19.49 \mathrm{~g} / \mathrm{L}$ in the control batch fermentation.

In an attempt to increase the solvent concentration in the permeate solution, the working volume of the fermentor was increased to $1.5 \mathrm{~L}$. Fresh feed with $240 \mathrm{~g} / \mathrm{L}$ glucose was 
supplied into the fermentor, and the dilution rate was decreased to $0.0081 \mathrm{~h}^{-1}$. A steady state was attained after $12 \mathrm{~h}$ of PV startup; the average residual glucose concentration was $25.31 \mathrm{~g} /$ $\mathrm{L}$ throughout the continuous fermentation period of $268 \mathrm{~h}$. The results are given in Table 2 . The increasing working volume

Table 2. Steady-State Solvent and Acid Concentrations in Continuous ABE Fermentation-PV Coupled Process at a Dilution Rate of $0.0081 \mathrm{~h}^{-1}$

\begin{tabular}{lcr} 
& retentate & permeate \\
acetone $(\mathrm{g} / \mathrm{L})$ & 0.71 & 28.36 \\
ethanol $(\mathrm{g} / \mathrm{L})$ & 0.42 & 4.09 \\
butanol $(\mathrm{g} / \mathrm{L})$ & 2.46 & 73.50 \\
total solvents $(\mathrm{g} / \mathrm{L})$ & 3.59 & 106.76 \\
acetic acid $(\mathrm{g} / \mathrm{L})$ & 0.48 & 0.42 \\
butyric acid $(\mathrm{g} / \mathrm{L})$ & 0.52 & \\
total acids $(\mathrm{g} / \mathrm{L})$ & 1.00 & 0.42 \\
Operated at $37^{\circ} \mathrm{C}$ for $288 \mathrm{~h}$. & & \\
\hline
\end{tabular}

induced an increasing of total solvent amount in the fermentor; therefore, the solvent concentration in the fermentor was higher than that with the relatively higher dilution rate of $0.0117 \mathrm{~h}^{-1}$. This resulted in a higher solvent concentration in the permeate solution of $106.76 \mathrm{~g} / \mathrm{L}(73.50 \mathrm{~g} / \mathrm{L}$ butanol, 28.36 $\mathrm{g} / \mathrm{L}$ acetone, and $4.09 \mathrm{~g} / \mathrm{L}$ ethanol, respectively). Similar results were also observed by Friedl et al. ${ }^{22}$

To further increase the total solvent concentration in the permeate solution, the dilution rate was further decreased to $0.0038 \mathrm{~h}^{-1}$. To maintain the broth volume in the fermentor constant, a membrane with a lower membrane area of 0.0072 $\mathrm{m}^{2}$ and $1 \mathrm{~L}$ working volume were used. This resulted in an increase of the solvent concentration in the fermentor (see Table 3). In the coupled process, fresh medium with $280 \mathrm{~g} / \mathrm{L}$

Table 3. Steady-State Solvent and Acid Concentrations in Continuous ABE Fermentation-PV Coupled Process at a Dilution Rate of $0.0038 \mathrm{~h}^{-1}$

\begin{tabular}{lcr} 
& retentate & permeate \\
acetone $(\mathrm{g} / \mathrm{L})$ & 1.23 & 47.25 \\
ethanol $(\mathrm{g} / \mathrm{L})$ & 0.93 & 8.12 \\
butanol $(\mathrm{g} / \mathrm{L})$ & 3.81 & 104.63 \\
total solvents $(\mathrm{g} / \mathrm{L})$ & 5.97 & 160.00 \\
acetic acid $(\mathrm{g} / \mathrm{L})$ & 0.53 & 0.51 \\
butyric acid $(\mathrm{g} / \mathrm{L})$ & 0.48 & \\
total acids $(\mathrm{g} / \mathrm{L})$ & 1.01 & 0.51 \\
Operated at $37^{\circ} \mathrm{C}$ for $288 \mathrm{~h}$. & & \\
\hline
\end{tabular}

glucose was fed into the fermentor and the average residual glucose concentration was maintained at about $24.78 \mathrm{~g} / \mathrm{L}$. As expected, the acetone, butanol, ethanol, and total solvent concentrations in the permeate solution were increased to $47.25,8.12,104.63$, and $160.00 \mathrm{~g} / \mathrm{L}$, respectively. According to the Material Safety Data Sheet (MSDS) for butanol, the solubility of butanol in water is about $7.7 \%$ at $20{ }^{\circ} \mathrm{C}$. When the butanol concentration in the mixture solution is more than $8 \%$, the overall butanol solution undergoes phase separation. It was indeed observed that there were two phases in the permeate solution, i.e., the organic phase and the aqueous phase. The organic phase contained a higher concentration of $533 \mathrm{~g} / \mathrm{L}$ $\mathrm{ABE}$ with $446 \mathrm{~g} / \mathrm{L}$ butanol. Such a highly concentrated butanol solution would significantly reduce the energy consumption required in final product recovery by distillation. ${ }^{5,6}$ The aqueous phase contained $160.7 \mathrm{~g} / \mathrm{L}$ ABE with $89.6 \mathrm{~g} / \mathrm{L}$ butanol, which could be further concentrated by a second-stage PV system. ${ }^{23}$

Productivity, yield, glucose utilization rates, and conversions achieved under the three dilution rates for a long period of continuous operation are presented in Figure 7. The highest

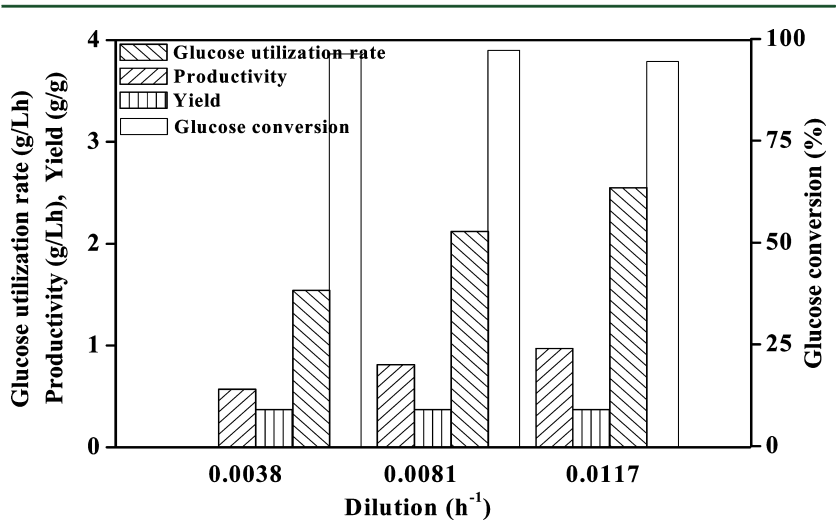

Figure 7. Comparison of solvent production in continuous $A B E$ fermentation-PV coupled process at three dilution rates.

productivity and glucose utilization rate obtained were 0.97 and $2.55 \mathrm{~g} / \mathrm{Lh}$, respectively, during continuous operation with the dilution rate $D=0.0117 \mathrm{~h}^{-1}$, which were $203 \%$ and $155 \%$ higher than those obtained in the control experiment, respectively. Decreasing the product recovery rate and dilution rate would help to increase the solvent concentration in the permeate solution; however, productivity and glucose utilization rates decreased. When dilution rate $D$ was decreased to $0.0038 \mathrm{~h}^{-1}$, the maximum average total solvent concentration reached $160.0 \mathrm{~g} / \mathrm{L}$ with productivity and glucose utilization rates of 0.57 and $1.54 \mathrm{~g} / \mathrm{Lh}$, respectively. The productivity and glucose utilization rates were also $78 \%$ and $54 \%$ higher, respectively, than those obtained in the control batch experiment without the PV process. The productivity enhancement was also found between continuous fermentation with and without the PV process by Hecke et al. ${ }^{8}$ They found that, as compared with continuous fermentation without the PV process as control, the continuous fermentation-PV coupled process increased the productivity to $0.30 \mathrm{~g} / \mathrm{Lh}$ from $0.13 \mathrm{~g} /$ Lh. It is interesting to note that there was little acid in the broth when the fermentation-PV coupled process was adopted. This indicates that most of the glucose and acids were converted to solvents. Therefore, a total solvent yield of $0.37 \mathrm{~g} / \mathrm{g}$ was obtained in the continuous fermentation-PV coupled process, which was higher than the yield $(0.32 \mathrm{~g} / \mathrm{g})$ in the control batch culture. This would improve the economic competitiveness of the process for butanol production from renewable resources. Experimental results also indicated that glucose conversions for the dilution rates of $0.0117,0.0081$, and $0.0038 \mathrm{~h}^{-1}$ were 96.34 , 97.18 , and $94.42 \%$, respectively.

3.3. Membrane Performance in Continuous Fermentation-PV Coupled System. Continuous fermentation experiments at three different dilution rates were carried out at steady state. The membrane performance during the fermentation-PV coupled processes was investigated in detail. Figure 8 shows the variation of total solvent fluxes and separation factors with operation time at the dilution rate of $0.0117 \mathrm{~h}^{-1}$. Under the experimental conditions examined, the 

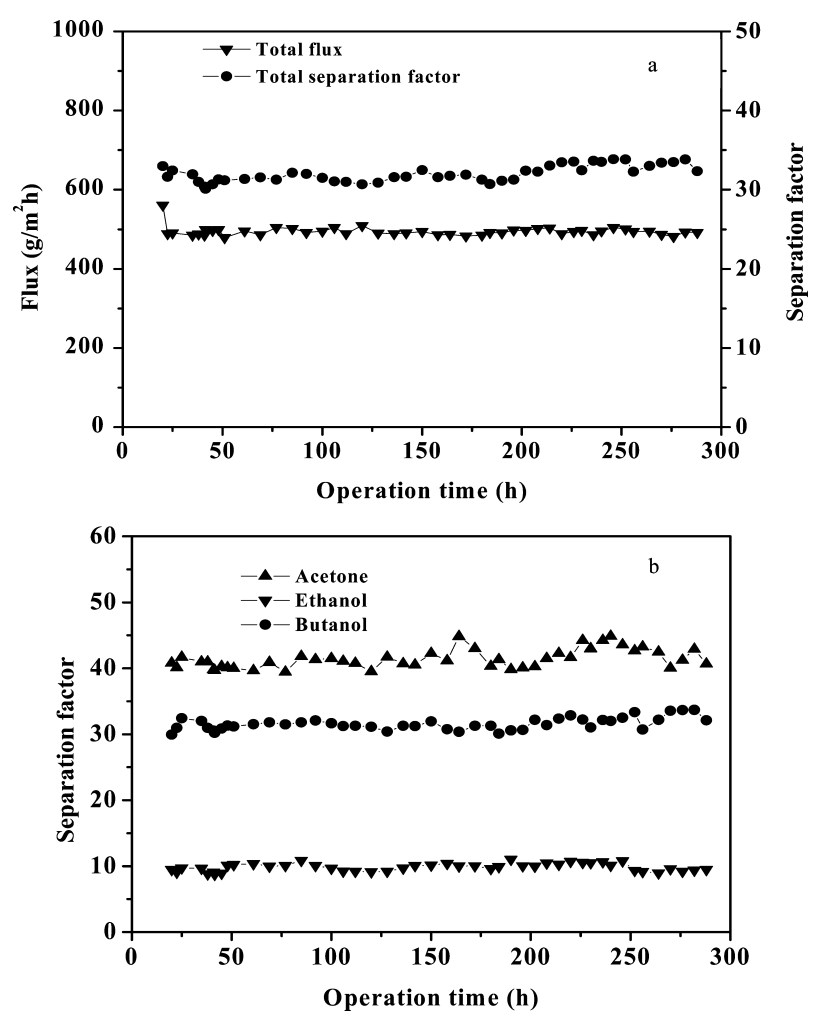

Figure 8. Pervaporation performance of the silicalite-1 filled PDMS/ PAN composite membrane in continuous ABE fermentation-PV coupled process; $D=0.0117 \mathrm{~h}^{-1}$.

total solvent fluxes dropped promptly from 561 to $491 \mathrm{~g} / \mathrm{m}^{2} \mathrm{~h}$ within the fermentation period from 20 to $25 \mathrm{~h}$. This was because the $\mathrm{ABE}$ concentration in the broth decreased as PV went on until a steady state was obtained (see Figure $5 b$ ), and according to the solution-diffusion model, individual solvent flux decreases with decreasing solvent concentration in the feed solution. The total flux maintained at approximately $486 \mathrm{~g} / \mathrm{m}^{2} \mathrm{~h}$ and lasted for $268 \mathrm{~h}$ without an obvious decrease. No significant variation in separation factor was observed, and the average separation factor of $\mathrm{ABE}$, acetone, butanol, and ethanol was 32.0, 41.4, 31.6, and 9.8, respectively (Figure 8b). These results indicated that the composite membrane was not fouled by the complex fermentation broth. A similar result was also obtained by Hecke et al. They reported that no fouling was observed during $475 \mathrm{~h}$ of continuous fermentation when a commercial PDMS membrane was coupled to ABE fermentation. ${ }^{8}$

For the experiments with the dilution rates of 0.0081 and $0.0038 \mathrm{~h}^{-1}$, the average total fluxes at steady state were 505 and $585 \mathrm{~g} / \mathrm{m}^{2} \mathrm{~h}$, respectively. According to the solution-diffusion model, the total flux is a function of ABE concentrations. Figure 9 shows the effect of average butanol concentration in the feed on butanol, total, and water flux during continuous $\mathrm{ABE}$ fermentation under different dilution rates. It can be seen that the water flux maintained at around $448 \mathrm{~g} / \mathrm{m}^{2} \mathrm{~h}$, whereas the butanol flux had a linear relationship with respect to the butanol concentration in the broth. Therefore, the total solvent flux increased with butanol concentration. Using eq 3, the overall mass transfer coefficient of butanol can be calculated to be $14.71 \mathrm{~mm} / \mathrm{h}$. This is $12.65 \%$ lower than that in butanol/ water solution $(16.84 \mathrm{~mm} / \mathrm{h})$. As compared with water flux in butanol/water solution (about $526 \mathrm{~g} / \mathrm{m}^{2} \mathrm{~h}$ ), water flux in the

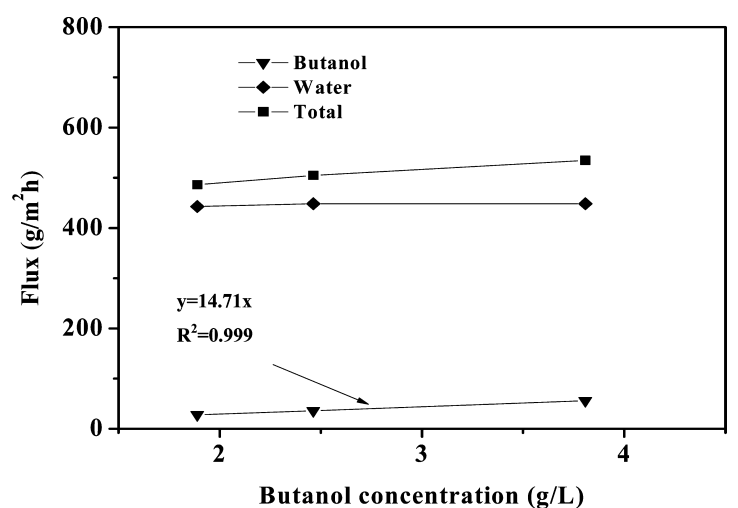

Figure 9. Fluxes of silicalite-1 filled PDMS/PAN composite membrane in continuous $\mathrm{ABE}$ fermentation-PV coupled process at three different dilution rates.

fermentation broth decreased by $14.83 \%$. These results indicated that the coupling effect occurred during the fermentation-PV process. The coupling effect of other components in complex fermentation systems on the target component has become a major concern for the PV. ${ }^{14}$ Lipnizki et al. ${ }^{24}$ investigated the influence of impermeable components on the permeation of aqueous 1-propanol mixtures in commercial PV. They found that $\mathrm{NaCl}, \mathrm{MgCl}_{2}$, and glucose tended to increase flux of the organic compared with a binary mixture, whereas citric acid, acetic acid, glycerine, and $\mathrm{Na}_{2} \mathrm{SO}_{4}$ acted to decrease flux. Zhou et al. ${ }^{11}$ reported that acetone and ethanol could cause a decrease of water flux in the separation of acetone and ethanol aqueous solutions using a dense silicalite-1 filled PDMS membrane. $\mathrm{Li}$ et al. ${ }^{14}$ investigated the recovery of butanol from $\mathrm{ABE}$ model solutions and binary solutions with the same butanol concentrations using a PDMS/dual support composite membrane and observed that the butanol fluxes in the $A B E$ model solutions were lower than that in the binary solutions. In the present work, the decrease of water flux and the overall mass transfer coefficient could be caused by other components in the $\mathrm{ABE}$ fermentation broth, such as acetone, ethanol, glycerine, or other metabolites. After the $\mathrm{ABE}$ fermentation operation with the coupled process, the thinfilm silicalite-1 filled PDMS/PAN membrane was flushed with deionized water for $2 \mathrm{~min}$, and then its PV performance was tested in butanol/water binary solution. The total flux and separation factor of the water-washed membrane were the same as those of the fresh membrane (Figure 10), implying that the coupling effect of the other composition on the membrane was reversible.

\section{CONCLUSIONS}

With the adoption of the thin-film silicalite-1 filled PDMS/ PAN composite membrane, continuous ABE production without periodic membrane cleaning could be applicable using the fermentation-PV coupled process. Compared to the control experiments, the coupled process exhibited a very high glucose consumption rate, productivity, and solvent yield. Moreover, the coupled process produced a high titer of butanol, which could decrease the energy consumption required in subsequent distillation for solvent recovery.

The membrane showed an excellent stability during $268 \mathrm{~h}$ of operation in the coupled process; i.e., flux and separation factor of the membrane were more or less constant during continuous $\mathrm{ABE}$ fermentation. Analyses of the overall mass transfer 


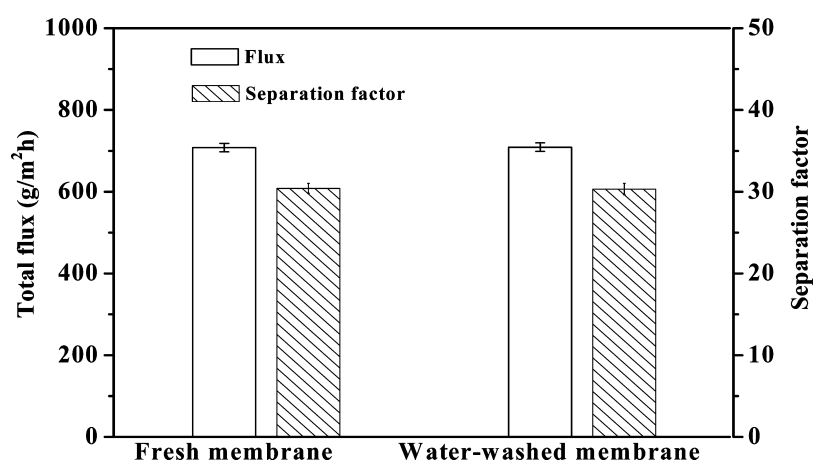

Figure 10. PV performance of the fresh and water-washed composite membranes. Feed: $10.5 \mathrm{~g} / \mathrm{L}$ butanol in water.

coefficient of the composite membrane showed that there existed a negative coupling effect of other components in the $\mathrm{ABE}$ fermentation broth on butanol flux and water flux. After the water wash, the performance of membranes could be restored as a fresh membrane. This work demonstrated that the silicalite-1 filled PDMS/PAN composite membrane was a promising membrane for butanol production with the fermentation-PV coupled process. In situ product recovery by PV could increase the economic competitiveness of biobutanol against the petroleum-based butanol.

\section{AUTHOR INFORMATION}

\section{Corresponding Author}

*Tel: 86-10-62650673. E-mail: yhwan@home.ipe.ac.cn.

Notes

The authors declare no competing financial interest.

\section{ACKNOWLEDGMENTS}

This work was supported by the National Natural Science Foundation of China (Grant no. 21176239), the National High Technology Research and Development Program of China (863 Program, Grant no. 2012AA03A607), and the Visiting Scholar Foundation of the Key Laboratory of Low-grade Energy Utilization Technologies and Systems (Chongqing University), Ministry of Education of China.

\section{REFERENCES}

(1) Kumar, M.; Gayen, K. Appl. Energy 2011, 88, 1999-2012.

(2) Qureshi, N.; Saha, B. C.; Cotta, M. A.; Singh, V. Energy Convers. Manage. 2013, 65, 456-462.

(3) Dürre, P. Curr. Opin. Biotechnol. 2011, 22, 331-336.

(4) Liu, H.; Lee, C.-f. F.; Huo, M.; Yao, M. Energy Fuels 2011, 25, 2426-2426.

(5) Badr, H. R.; Hamdy, M. K. Biomass Bioenergy 1992, 3, 49-55.

(6) Xue, C.; Zhao, J. B.; Lu, C. C.; Yang, S. T.; Bai, F. W. Biotechnol. Bioeng. 2012, 109, 2746-2756.

(7) Leland, M. V. J. Chem. Technol. Biotechnol. 2005, 80, 603-629.

(8) Hecke, W. V.; Vandezande, P.; Claes, S.; Vangeel, S.; Beckers, H.; Diels, L.; DeWever, H. Bioresour. Technol. 2012, 111, 368-377.

(9) Chen, C.; Xiao, Z.; Tang, X.; Cui, H.; Zhang, J.; Li, W.; Ying, C. Bioresour. Technol. 2013, 128, 246-251.

(10) Liu, G. P.; Wei, W.; Wu, H.; Dong, X. L.; Jiang, M.; Jin, W. Q. J. Membr. Sci. 2011, 373, 121-129.

(11) Zhou, H. L.; Su, Y.; Chen, X. R.; Wan, Y. H. Sep. Purif. Technol. 2011, 79, 375-384.

(12) Liu, X. L.; Li, Y. S.; Liu, Y.; Zhu, G. Q.; Liu, J.; Yang, W. S. J. Membr. Sci. 2011, 369, 228-232.

(13) Yi, S. L.; Su, Y.; Wan, Y. H. J. Membr. Sci. 2010, 360, 341-351.
(14) Li, S. Y.; Srivastava, R.; Parnas, R. S. Biotechnol. Prog. 2011, 27, 111-120.

(15) Zanati, E. E.; Hakim, E. A.; Ardi, O. E.; Fahmy, M. J. Membr. Sci. 2006, 280, 278-283.

(16) Vane, L. M. Biofuels, Bioprod. Biorefin. 2008, 2, 553-588.

(17) Li, S. Y.; Srivastava, R.; Parnas, R. S. J. Membr. Sci. 2010, 363, 287-294.

(18) Tashiro, Y.; Takeda, K.; Kobayashi, G.; Sonomoto, K.; Ishizaki, A.; Yoshino, S. J. Biosci. Bioeng. 2004, 98, 263-268.

(19) Hecke, W. V.; Tim, H.; Wever, D.; Heleen. Bioresour. Technol. 2013, 129, 421-429.

(20) Qureshi, N.; Meagher, M. M.; Huang, J. C.; Hutkins, R. W. J. Membr. Sci. 2001, 187, 93-102.

(21) Gapes, J. R.; Nimcevic, D.; Friedl, A. Appl. Environ. Microbiol. 1996, 62, 3210-3219.

(22) Friedl, A.; Qureshi, N.; Maddox, I. S. Biotechnol. Bioeng. 1991, $38,518-527$.

(23) Wan, Y. H.; Li, J.; Chen, X. R.; Su, Y.; Qi, B. K.; Shen, F., China patent CN 201210265526.3, Sep 14, 2012.

(24) Lipnizki, F.; Hausmanns, S.; Field, R. W. J. Membr. Sci. 2004, 228, 129-138. 